\title{
The sexuality of Quebec women with cervical cancer: Looking for love despite radiotherapy's trauma to their sexual body
}

\section{by Karine Bilodeau and Louise Bouchard}

\begin{abstract}
The purpose of this phenomenological study was to describe the experience of sexuality of middle-aged Quebec women living with cervical cancer. Ten women accepted to take part in the study. The findings reveal a new outlook on sexuality, as these women refocus their positions on their lives, their conjugal relationships and the adverse effects of therapies. The participants expressed the will to combine feelings of love with sexual pleasures. They all felt the need to talk about the embarrassing and traumatizing effects of treatment on their sexuality. These findings raise the need for nurses to recognize these women's sexual concerns and to further research in this area.
\end{abstract}

Key words: sexuality, lived experience, cervical cancer, radiation therapy, side effects, mid-life

The World Health Organization (World Health Organization, 1975) defines sexuality as a subjective and multidimensional phenomenon that is part of individuals' overall health. The OMS refers to it as "sexual health", which implies an integration of biological, emotional and social aspects of the sexual self and the shaping of personality, communication and love. The expression of sexuality by women is affected by their cervical cancer. Some authors state that the sexual dysfunctions experienced by these women may be caused by the side effects of cancer treatments: vaginal shrinkage and dryness, changes in vascularization, and vaginal tissue necrosis, dyspareunia and premature menopause causing hot flashes and mood swings (Langhorne, Fulton, \& Otto, 2007). However, scientific research conducted about women with cervical cancer did not much address their sexuality from a global perspective except for a few qualitative-design studies. It is clear that among the scientific papers dealing with their sexuality, more have studied it from a physical and quantitative angle than an experiential one (Bergmark, Avall-Lundqvist, Dickman, Henningsohn, \& Seineck, 1999; BourgeoisLaw \& Lototocki, 1999; Heylock \& McGinn, 1998). In these studies,

\section{About the authors}

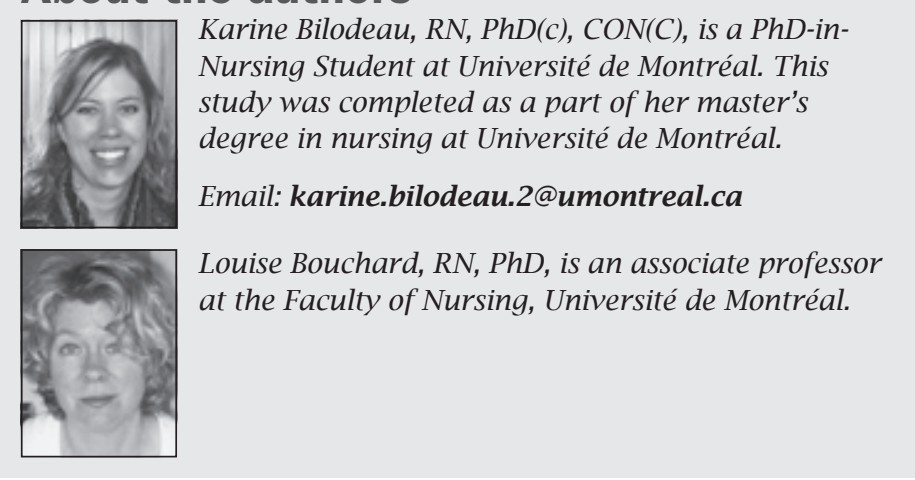

researchers are using such indicators as number of orgasms, frequency of sexual relations, and sexual satisfaction of women living with cervical cancer. While they develop an objective profile of their sexuality, these quantitative studies do not promote a holistic comprehension of how these women experience their sexuality in their daily lives and the significance it holds for them.

Some qualitative-design studies have explored the lived experience of sexuality for women living with cervical cancer. According to their findings, sensuality, intimacy and self-image, closely linked to the role of mother, woman and partner, are experienced differently after a cancer diagnosis. Some women report that they experience a loss of libido and that they remove themselves emotionally from the sexual act, which remains traumatizing, even several years after diagnosis (Ashing-Giwa, et al., 2004; Burns, Costello, Ryan-Wooley \& Davidson, 2007; Butler, Banfield, Sveinson, \& Allen, 1998; Juraskova, Butow, Robertson, Sharpe, McLeod, \& Hacker, 2003). Ashing-Giwa and collaborators (2004) address an ethnocultural dimension by stating that perceptions related to conjugal relationships, sexual intimacy and treatment side effects depend on the ethnicity of the women in their study. Other studies exploring the sexuality of women living with various gynaecological cancers point to an affective renewal with their spouses and difficulties with intimacy and having to say goodbye to reproduction (Howell, Fitch, \& Deane, 2003; Pilkington \& Mitchell, 2004). The abovementioned studies were conducted with Anglophone women from Canada, the United States and Europe. Following the lead of Ashing-Giwa and collaborators (2004), we believe that studying the sexuality of Francophone women from Quebec may yield a different perspective on this phenomenon.

This study aims to obtain a better understanding of the sexuality of middle-aged Quebec women whose cervical cancer is being treated with radiation by taking into account their own words, values and life circumstances.

\section{Method}

Initiated by Husserl (1976) at the beginning of the 20th century, phenomenology is an epistemological approach that aims to understand lived experience as a source of knowledge. Through narrative material, phenomenology enables one to enter the subjective world of people. Under the ontological postulates of phenomenology, the individual is the only one who can describe the meaning ascribed to his or her life experiences, from his or her own consciousness, life ethics, history and context (Oiler-Boyd, 1981).

The research project was submitted to the research ethics committee of a Montreal hospital centre specializing in gynecological oncology and radiation oncology. Physicians and nurses working in these areas were invited to recruit women during followup appointments. The convenience sample was composed of 10 women who met the following criteria: 40 to 60 years of age; having completed their radiotherapy treatments for cervical cancer at least six months before; belonging to a French-speaking family established in Quebec for a minimum of two generations. The age limitation was supported by the heightened prevalence of cervi- 
cal cancer among women aged 40 to 60 (Goggin, 2005) and by corresponding life cycle, i.e., middle age (Hunter, Sundel, \& Sundel, 2002). Ten interviews lasting on average 60 to 90 minutes were completed. At the time of the interviews, nine women had been living as part of a couple for more than 10 years. Five participants had received their last treatment less than seven months before while the other five had received it at least two years previous. All had received chemotherapy and radiotherapy treatments, both external and internal (brachytherapy for the latter).

The transcribed data were subjected to a thematic analysis according to the method suggested by Giorgi (1997), which includes the following steps: 1) Transcribe the interviews in full; 2) Retain a global sense of the participants' narration; 3) Discriminate units of meaning by isolating words, phrases or ideas; 4) Transform the participants' spontaneous expressions into more abstract expressions that reveal their meaning; and 5) Synthesize units of meaning (themes) into a consistent and invariable description (essence) of the phenomenon under study. According to Giorgi (1997), the scientific rigor of a phenomenological study is checked against the criteria of trustworthiness and credibility. Trustworthiness, that is to say the matching of our results with the experience described by the participants, was obtained through bracketing, an exercise whereby the student researcher sets aside her presuppositions through reading the interviews multiple times and through interrater reliability by comparing all of her own analytical results with those of her research supervisor. Credibility, meaning that the results match the reality, is achieved through the diversity of lived experiences by the participants and through using interviews until redundancy is reached within the gathered data (Giorgi, 1997). Ten women proved to be a sufficient number for the essence of the sexuality phenomenon to emerge while remaining true to the uniqueness of the individual participants' lived experiences, as is evidenced by some of the verbatim excerpts presented in the results section. Credibility was also achieved by comparing our results with those of noted scientific authors in this field.

\section{Results}

The global essence of the sexuality of Quebec women living with cervical cancer can be given the following description: since the onset of cancer, these women live their sexuality as an intimate experience shared with their spouse, the meaning of which evolves with time. A sexuality that was perceived more as opportunities for sexual activities makes room for the expression of an intimacy that is more appreciated for what it offers from an emotional perspective. However, all participants explain that the sexual act, while occupying an important place in their lives, evolves toward a more global representation of sexuality where physical intimacy and quest for love are intertwined. This evolution of the meaning of sexuality from a physical dimension to a more emotional dimension would be influenced by three concomitant phenomena: a different outlook on life, an unshakeable support from the spouse and the emergence of treatment-related side effects. For our study participants, time proves to be an important component in the experience of sexuality. The five women whose diagnosis had been announced more recently report living with much more anxiety, wonder more about the causes of their disease and are more worried about recurrence than the other participants whose diagnoses date back two to five years. The latter feel they are more able to revisit their positions on their lives and sexual lives, despite experiencing significant side effects, as well.
Three central themes emerged from the data analysis: Living a global change in relation to one's life; Seeing the conjugal relationship differently; Seeing sexuality in a different way. The latter includes two sub-themes, In the search of love and Living in a sexual body traumatized by radiotherapy.

\section{Living a global change in relation to one's life}

While asking themselves the very first questions, participants spontaneously reframed their sexuality relative to their lives and conjugal relationships. According to their statements, the onset of cancer caused a global and gradual change in their life values: the participants no longer see life "in the same way", focus more on themselves and their own needs and re-evaluate their priorities. The uncertainty and fear of a recurrence described by Hélène** as the "sword of Damocles hanging over one's head" are experienced by most of the participants, which incites them to revisit the significance they assign to life. They say that they "truly enjoy life and no longer dwell on trivial things," and have a deeper appreciation for the present moment with their family and spouse. One participant speaks of cancer as a rebirth, as "a slap in the right place," that helped her focus her priorities on her family and gave new impetus to her life. Three participants did not feel the need to talk about life in general and about the changes that their cancer experience may have generated. Their statements were more focused on their conjugal relationships and sexuality.

\section{Seeing the conjugal relationship differently}

This theme highlights how essential and significant the relationship with the spouse was in the new outlook the participants had on their lives and sexuality. Appreciating life more fully meant appreciating the moment with one's spouse. Eight participants expressed the importance of their spouses' presence and their astonishment at the amount of attention they gave them throughout their experience of living with cancer. Anne mentioned the "evolution of the relationship with her spouse," while Béatrice spoke of "mutual rediscovery". Some of the participants spoke of "my buddy, my lover" and of their conjugal relationship by joining their hands to illustrate this greater closeness with their spouse since the onset of cancer, as witnessed by the following excerpts:

It brought us closer for sure, because it is often when you're going through emotional periods like receiving a diagnosis, that's when you realize whether you care for your spouse and he cares for you or not, because you need his support. (...) I would say he was paying more attention to me, to my needs, my non-sexual needs, I mean. (Danielle)

You always have highs and lows, there are times when you're tired, but that's nothing serious, I say to myself that life with him is rather nice that I think I would go back to having cancer to start this once again because it's so beautiful. Before, it was too platonic. There comes a time when you have no other choice but sit down with your husband and discuss your sexuality with him in the light of cancer, so the fact I had cancer kind of opened a door (for talking). (Jeanne)

However, two participants, Irène and Francine, experienced problems in their conjugal relationships. Irène's marital relationship came to an end after her treatments. She had "drawn an $x$ " on sexual activities and was unable to convey her difficulties, desires and needs to her spouse. She thought that he would not understand and that he could not consider sexuality from any other angle than that of the sexual act. Moreover, her spouse did not want her

\footnotetext{
* The terms in italics are excerpted from the verbatim.

** Pseudonyms are being used to protect the participants' confidentiality: Anne, Béatrice, Claudia, Danielle, Élyse, Francine, Guylaine, Hélène, Irène and Jeanne. None of Élyse's words have been included in this article.
} 
to mention her cancer to her family because of the misgivings people might have about him being responsible for transmitting human Papillomavirus (HPV). Three other participants, Claudia, Hélène and Jeanne, also voiced their concerns and misgivings about their sexual pasts and their spouses' faithfulness. They felt awkward talking about the taboo of cervical cancer that one "gets through sex." It is worth noting that, throughout ours interviews, information on HPV and its sexual transmission were well-publicized. Here are a few excerpts:

I got cancer (...) a virus which one gets sexually. It is as if I begrudge myself for letting myself being swept up by this liberating sexuality that I had, for having so much pleasure that I ended up having cancer (...). Maybe it's my spouse's fault because (...) he cheated on me and it's certainly from him that I got it (cancer) (...) I try to tell myself that it's not his fault and there are times when I tell myself it's his fault. My husband did not want me to talk about him... I told him, listen, they talk about the vaccine on TV, family members are gonna know that. (Francine)

So the doctor tells you: you must have caught a venereal disease to get this cancer. The only man I ever slept with is my husband. So, it's not me who went out there to get it (HPV). So I resented him for that. (...) It took six months for my grudge to disappear. (Jeanne)

\section{3a. Seeing sexuality in a different way: Seeking love}

Following the onset of cancer, the participants gradually changed the conception they had of sexuality by granting as much-if not more-importance to the affective, relational and human dimensions of sexuality than to its physical dimensions, as related by Anne and Hélène: "Before it was just sex. Nowadays, caressing brings me warmth, gives it a human aspect; it's more true" (Anne). "What's important is that it's more focused on affection. It is about caressing and being tight against one another, this is as important as sexual intercourse" (Hélène). Eight participants say they seek in sexuality opportunities for affection, love, hugs, intimacy, making love, wellbeing, gentleness, warmth, comfort and closeness. Sexual contacts, designated by terms such as sex, penetration, orgasm, kisses, bestiality, and genitality, are not set aside: "I want sexuality to be there, that he still wants me. I want him to find me beautiful; I want him to be beautiful. I want to feel like having him" (Guylaine), but for the majority of participants, these sexual contacts now have a different place in their lives. Even though they all report being less active physically, having fewer sexual relations and a less-intense libido since the onset of cancer, they describe their sexuality as having grown and being more satisfying. The women in our study are first and foremost seeking sexual satisfaction in a human and intimate report with their spouse. Béatrice's statement exemplifies the change in meaning:

Sexuality fell to second and third place... It is important and it is there, but it's more comforting and more embracing; it covers me and I'm OK with that. When we were making love before, well, it was to reach orgasm... (Today) it does not need to be a sexual relation based on penetration (...) I discovered with my husband that... just snuggling up against one another... that's a new kind of sexual relation, because love is always there with us (...) for sure that it (sexuality) still is important. (Béatrice)

Study participants differentiate between the way they conceive their own sexuality and the way their spouses do. According to them, their husbands attach greater importance to sexual acts, to climax and frequency of sexual relations. "Our sexuality is linked with our brains, but with them it is really connected to their penis," Danielle states. Moreover, Béatrice thinks the change in how she perceives her sexuality is possibly due to menopause: "No doubt that my libido has seen a huge drop. It may be menopause; I am not a 30year-old woman who's had cancer." (Béatrice)

\section{3b. Seeing sexuality in a different way:}

Living in a sexual body traumatized by radiotherapy

To illustrate this sub-theme, participants were grouped according to the time elapsed between the end of their radiation treatments and the interviews. The verbatim excerpts essentially concern the side effects of brachytherapy, the experience of undergoing this treatment and the varied reactions to vaginal dilation exercises.

Claudia, Danielle and Francine are among the women who completed their radiation therapy less than eight months before the interviews were held. Claudia described her sexuality as being a "chore", during and after her radiation treatments: "I had no libido, none at all, you see, nothing, niet." Claudia suffered through bloody and foul-smelling vaginal discharge following radiation treatments, which made it impossible for her to let herself go during sexual relations. She said, "It was making me feel extremely uneasy even though I have been with my husband for 20 years." As she is feeling "smaller inside" referring to her vaginal stenosis, she can no longer adopt former sex positions. Brachytherapy caused bladder problems that required the installation of urethral catheters. Claudia by far preferred using a vaginal dilator**** to starting regular sexual activities anew with her spouse. She added that the dilator can be handled on a daily basis, but "My husband, I would not have had him every day."

Following her treatments, Danielle was "afraid to feel pain" during sexual relations, due to vaginal dryness and dyspareunia. She, too, preferred dilation exercises to resuming sexual activities, because she did not feel she was ready to initiate them. Danielle gave an emotional description of her experience with brachytherapy, and the interview had to be interrupted so that she could regain control over her emotions. Here is her story:

It was painful and then the catheter was too large (...), they did not have the right type (...) so you hear all that, you're not unconscious and the nurse gives you some medication to help you relax (...) and I said to the nurse: 'Is it normal that I feel all that'... so the doctor tells her: "Give her another small dose" to make me softer. And it's full of people, there is an intern, another intern, a young woman, a nurse from the floor who came to assist me and the comings and goings are such that I felt like I was in the subway, it was so confusing (...) the intern said to the other intern, look, touch, you'll see what it is and the latter, he did not talk to me, he did not look at me, did not ask me who I was, did not say hello to me-nothing-he simply put on a pair of gloves, he put this on and he penetrated me, he did touch there, thank you very much-goodbye, he turned away, removed his gloves and left. I felt like a headless chicken, you know when you gut a chicken, exactly like that. When it's like that, you don't have any choice, you're pretty much at their mercy (...) I said, look here, it's over, they're not touching me anymore. Not one of them is gonna touch me, I said to myself, it's up to you to decide, it's your body. (Danielle)

Francine states that she led in the past an active sexual life she describes as multiorgasmic, and that she felt "good as a woman" and fulfilled before her cancer diagnosis. After her treatments, Francine no longer saw sexuality in the same light. She explains:

:*** Plastic tube with a rounded extremity used to dilate the vagina. Following cervical cancer treatments, it is usually recommended to insert it in the vagina once a day for 10 minutes to prevent vaginal stenosis. 
After my treatments, I had this huge fear. I had no craving for sexuality, none at all and I felt absolutely nothing. At the beginning, it was burning, it hurt...at the beginning, in my head, for me, I am burnt from the inside. (...) I have no longing for him (her spouse) to make me come because I fear it's going to end up with penetration and I don't feel like being penetrated. As far as I am concerned, sex is not back on, for the time being at least. This is a cancer that hits you at your most intimate. So, now there is less sexuality. I feel kind of embarrassed. Yet, I was the type of woman who talked about sexuality the way one talks about food (laughs). I was not a bit embarrassed by it, but maybe I should tell him (her spouse) what to do, but I am worried about him taking it the wrong way. I have always been the one taking the first steps. (Francine)

Francine deplored the lack of physical intimacy during her brachytherapy sessions. She felt lonely in spite of a bedside nurse being present:

Brachytherapy traumatized me a lot, it was really painful. There you are, spread wide open, in a room where it's cold, there are many people around, he gives you injections so that your head's gone, drugs, you're tied to wires, and there you are spread open for a good half hour and you are alone. Well there's the nurse. So you're not alone, as there is a nurse with you who talks to you, who asks you if you're doing fine, but it's your inner part, I don't know how to explain this (cries)-it's hard. It gets to the deepest part of you,they get to completely burn your whole intimacy. (Francine)

Even after these treatments ended, Francine felt uneasy at follow-up appointments with a male technologist who performed the brachytherapy treatment. She says that from now on this staff member "knows me in my most intimate, so I don't feel like him recognizing me (...) He has had a good view of all of me. He knows everything about me." (Francine)

As with Claudia and Danielle, Francine appreciates the personal control she can exercise by using a vaginal dilator.

This (dilator) does not hurt, but I am the one who pushes it in, I am the one who deals with it, it's my own business because it's not a penis. It's not the same thing. If it hurts, I remove it and I don't use it very often. (Francine)

Even though Anne, Béatrice, Guylaine, Irène and Jeanne finished their treatments more than two years previously, they experience the delayed side effects that still impact their sexual lives. Since her radiation treatments, Anne describes herself as "impotent" and "devoid of sexual desire." Béatrice suffered from cystitis, which was described as a "cemented bladder" and manifested itself as abdominal pain, nocturia and polyuria and made her worry about feeling pain during sexual relations involving penetration. The vaginal dilator "reminded her of a penis", which forced her not to use it. Guylaine complains of vaginal irritation and bleeding and great fatigue that trouble her each time she has sexual relations. Jeanne experienced vaginal atrophy and some dyspareunia, which moderated sexual relations with her spouse. She preferred regular sexual relations to vaginal dilation exercises, but to no avail. Her vagina closed up to the point where she felt like "a seven-year-old child" and sexual relations became very painful for her. Finally, Irène qualified her brachytherapy as a violent treatment. She underwent a colostomy that reduced her sexual performance: "If you're unable to move, you're like a plaster statue... it's not obvious for the other person, I felt bad about it." Using a vaginal dilator caused pain and worries it would "bring about new problems". Irène says that after her treatments she was very tired and no longer had any sexual libido. She also suffered from a change in body image, as she gained a lot of weight; she reports feeling less beautiful and desirable.
Our research yielded novel data regarding the possible side effects of treatments on the sexuality of study participants. All felt a strong need to talk about it at the interviews. All of them without a single exception experienced significant side effects after radiation therapy such as dyspareunia, vaginal stenosis, polyuria, vaginal discharge and bleeding, and decreased libido. Delayed side effects were experienced such as cystitis, intestinal obstruction, polyuria and installation of a colostomy. The results we obtained are unequivocal: immediately following radiation treatments, side effects are both troublesome and traumatizing and may last over a long period of time. Many women gave up sexual relations. Finally, it is relevant to note the diversity of experiences relative to the acceptability and use of a vaginal dilator.

\section{Discussion}

According to our study results, the sexuality of women participants living with cervical cancer takes on a new course following their diagnoses. They appreciate and welcome it in their lives for its relational and affective qualities. Sexuality is part of a new positioning towards life and the conjugal relationship, which has changed since the cancer diagnosis and treatments. The spouse's support played a vital role in this evolution of perspective on sexuality. Most participants reported a closer relationship and a more open communication with their partners. These results are corroborated in studies by Butler and colleagues (1998) and Juraskova and colleagues (2003). Furthermore, Burns, Costello, Ryan-Woolley and Davidson (2007) reported significant conjugal tensions following cervical cancer treatment, but this was not supported by our own results, except for a single participant.

It is troubling to observe the degree to which radiation treatment side effects have been debilitating for many of the women in our study and devastating for their sexual lives. The experience of brachytherapy was described as being humiliating, distressing and painful, leaving injured the part of the body that's symbolically associated with their sexuality and is revealing all of them and their deepest intimacy. The expression "it comes to tear at your innermost," as reported by one of the participants, sums up perfectly what these women went through. The numerous physical discomforts caused by radiation treatments such as dyspareunia, vagina bleeding, foul odours, polyuria and vaginal shrinkage greatly hampered the resumption of sexual relations. Vaginal dilators recommended to prevent vaginal stenosis were perceived in different ways by the participants. Some said they preferred the dilator to resuming sexual relations, because it helped them tame their bodies anew and exercise a certain degree of power and assertiveness with their spouses by deliberately choosing the time and manner in which to start sexual relations anew. Others rejected this device because it reminded them too much of their spouses' sex organs. This particular result underlines the need to consider the singularities and preferences of individual women when deciding on recommending the use of a dilator.

An original result from our study relates to the media impact on cervical cancer achieved by advertisements related to HPV. Some participants questioned their own past relations and their spouses' or reported feeling embarrassed to talk about their cancers with family members because of the potential blame the latter could lay on their sexual conduct or that of their spouses. Results reveal the place of the media in the development of social representations by women about their bodies and, in the present case, cervical cancer.

Following the disclosure of the study results, the care teams at the centre where the study took place mobilized to rethink certain care practices in order to protect the intimacy and modesty of the women receiving radiation therapy. Efforts were made to ensure that the information on this type of treatment and its effects on sexuality are communicated to them at their own pace and according to their own wishes. Bedside nurses were invited to address sex- 
uality with these women even if this topic is sometimes considered delicate and confidential. In our study, it was surprising to see how keen the participants were to share their own experience of sexuality spontaneously and uninhibitedly. A recommendation was put forward to the health care team to establish a meeting group for this population, so that they could share their sexual concerns and break taboos and beliefs regarding sexuality.

There are some limits to our study, and further research in this subject area would be welcome. A few women refused to participate in the study because they were single. It is possible that social desirability introduced a bias in the recruiting of these women, as they were worried about not giving answers in keeping with socially accepted values. It would be interesting to question single women on the meaning they assign to their sexuality in a context where they do not share their daily lives with partners. Also, could it be that middle years and the experience of menopause, two factors reported in the literature as having the potential to create new sexual energies (Daniluk, 1998), contributed to the change in the vision of sexuality by the women participants in our study? Answering these questions would deserve further empirical investigations. Lastly, our study does not reveal whether Francophone female Quebecers experienced their sexuality differently from women of other origins. Are their openness, ease and volubility in expressing themselves on a topic as delicate and private as sexuality indicative of a cultural distinctiveness in our study? We're

\section{References}

Ashing-Giwa, T.K., Kagawa-Singer, M., Padilla, V.M., Tejero, S.J., Hsio, E., Chhabra, R., ... Tucker, M.B. (2004). The impact of cervical cancer and dysplasia: A qualitative, multiethnic study. PsychoOncology, 13(10), 709-728.

Bergmark, K., Avall-Lundqvist, E., Dickman, P.W., Henningsohn, L., \& Seineck, G. (1999). Vaginal changes and sexuality in women with a history of cervical cancer. New England Journal of Medicine, 340, 1383-1389.

Bourgeois, L. (2009). Le processus d'adaptation de conjoints dont la femme est atteinte d'un cancer de l'ovaire. Montréal : Université de Montréal.

Bourgeois-Law, G., \& Lotocki, R. (1999). Sexuality and gynaecological cancer: A need assessment. The Canadian Journal of Human Sexuality, 8, 231-240.

Burns, M., Costello, J., Ryan-Woolley, B., \& Davidson, S. (2007). Assessing the impact of late treatment effects in cervical cancer: an exploratory study of women's sexuality. European Journal of Cancer Care, 16(4), 364-372.

Butler, L., Banfield, V., Sveinson, T., \& Allen, K. (1998). Conceptualizing sexual health in cancer care. Western Journal of Nursing Research, 20(6), 683-705.

Daniluk, C.J. (1998). Women's Sexuality: Across the Life Span. New York: The Guilford Press.

Fitch, M., \& Allard, M. (2007). Perspectives of husbands of women with breast cancer: Impact and response. Canadian Oncology Nursing Journal, 17(2), 66-71.

Giorgi, A. (1997). De la méthode phénoménologique utilisée comme mode de recherche qualitative en sciences humaines: théorie, pratique et évaluation. Dans Poupart, Deslauriers, Laperière, Mayer et Pires (dir.), La recherche qualitative : Enjeux épistémologiques et méthodologiques (p. 341-364). Montréal : Gaëtan Morin.

Goggin, P. (2005). Le dépistage du cancer du col utérin: comment le rendre optimal. Communication présentée aux Journées annuelles de santé publique, Montréal, Canada. Retrieved May 5, 2007 from http://www.inspq.qc.ca/jasp/archives/pdf /2005/ JASP2005-VPH-Goggin.pdf unable to answer this question at present. It would be desirable to pursue hermeneutic or ethnographic-type studies exploring the richness of meanings for words and phrases related to sexuality drawn from the folk culture in order to expand knowledge in this research area. In our study, the word "sexuality" proved to be both complex and polysemous. Finally, critical research is highly recommended in exploring the representation of the "innermost" bodies by women with cervical cancer following the intrusive radiation procedures and the power exerted by expert and medical knowledge on the female body.

\section{Conclusion}

According to our study results, the cancer experience is a significant precursor to a global change process concerning the general outlook on life, especially sexuality and conjugal relationship. Women living with cervical cancer must deal with several acute side effects-mostly caused by radiotherapy-which directly affect the expression of their physical sexuality. Following their treatments for cervical cancer, the majority of interviewed women reported their quest for love and their will to integrate their amorous feelings and married lives with the pleasure brought on by sexual relations. It is our belief that this research is relevant to nursing science, as the results yielded a more sensitive and attentive approach to the lived experience of women treated for cervical cancer and generated new ways of caring for them.

Heylock, J.P., \& McGinn, A.K. (1998). Women's cancers: How to prevent them, how to treat them, how to beat them. Salt Lake City: Hunter House Publishers.

Howell, D., Fitch, M., \& Deane, A.K. (2003). Impact of ovarian cancer perceived by women. Cancer Nursing, 26(1), 1-9.

Hunter, S., Sundel, S.S., \& Sundel, M. (2002). Women at midlife: Life experiences and implications for the helping professions. Washington: NASW Press.

Husserl, E. (1976). La crise des sciences européennes et la phénoménologie transcendantale traduit de l'allemand et préfacé par Gérard Granel. Paris: Gallimard.

Juraskova, I., Butow, P., Robertson, R., Sharpe, L., McLeod, C., \& Hacker, N. (2003). Post-treatment sexual adjustment following cervical and endometrial cancer: A qualitative insight. PsychoOncology, 12, 267-279.

Kylstra, W.A. (1999). Sexual outcomes following treatment for early stage gynaecological cancer: A prospective multicenter study. International Journal of Gynaecological Cancer, 9(5), 378-395.

Langhorne, M.E., Fulton, J.S., \& Otto, S.E. (2007). Oncology Nursing (5th ed.). Philadelphia: Mosby Elsevier.

Oiler-Boyd, C. (1981). The phenomenological approach in nursing research. Nursing Research, 31(3), 178-181.

World Health Organization. (1975). Education and treatment in sexuality: The training of health professionals. Geneva: World Health Organization, Technical Report Series \#52.

Pilkington, F.B., \& Mitchell, J.G. (2004). Quality of life for women living with a gynaecologic cancer. Nursing Science Quarterly, 17(2), 147-155.

Weijmar-Scultz, W.C.M., \& Van De Wiel, H.B.M. (2003). Sexuality, intimacy, and gynecological cancer. Journal of Sex and Marital Therapy, 29(8), 121-128.

Wimberly, S.R., Carver, C.S., Laurenceau, J.P., Harris, S.D., \& Antoni, M.H. (2005). Perceived partner reactions to diagnosis and treatment of breast cancer: Impact on psychosocial and psychosexual adjustment. Journal of Consulting and Clinical Psychology, 73, 300-311. 